\title{
Correction to: An analysis of the kinetics of molecular response during the first trimester of treatment with nilotinib in newly diagnosed chronic myeloid leukemia patients in chronic phase
}

\author{
Juan Luis Steegmann ${ }^{1}\left[\begin{array}{l}{[} \\ \text { - Dolors Colomer }\end{array}{ }^{2}\right.$ Maria-Teresa Gómez-Casares $^{3} \cdot$ Valentín García-Gutiérrez $^{4}$. \\ Guillermo Orti ${ }^{5}$ - Angel Ramírez-Payer ${ }^{6} \cdot$ Eduardo Olavarria $^{7} \cdot$ Ferrán Vall-llovera $^{8} \cdot$ Pilar Giraldo $^{9}$ • \\ Eulogio Conde $^{10} \cdot$ Rolando Vallansot $^{11} \cdot$ Jose Luis López-Lorenzo $^{12}$ - Luis Palomera ${ }^{13}$ - Alberto Álvarez-Larrán ${ }^{14}$. \\ Venancio Conesa $^{15}$ - Guiomar Bautista ${ }^{16}$ - Laura Casas $^{17} \cdot$ Frank Giles $^{18}$ - Andreas Hochhaus ${ }^{19}$. \\ Luis Felipe Casado-Montero ${ }^{20}$
}

Published online: 23 October 2017

(C) The Author(s) 2017. This article is an open access publication

\section{Correction to: J Cancer Res Clin Oncol (2017) 143:2059-2066 DOI 10.1007/s00432-017-2445-z}

The article "An analysis of the kinetics of molecular response during the first trimester of treatment with nilotinib in newly diagnosed chronic myeloid leukemia patients in chronic phase", written by Juan Luis Steegmann, Dolors Colomer, Maria-Teresa Gómez-Casares, Valentín García-Gutiérrez, Guillermo Ortí, Angel

The online version of the original article can be found under doi:10.1007/s00432-017-2445-z.

Juan Luis Steegmann

jlsteegmann.hlpr@salud.madrid.org;

jlsteegmann@gmail.com

1 Hematology Service, Advanced Therapies in Oncohematology, IIS-IP, Hospital de la Princesa, Madrid, Spain

2 Unitat d' Hematopatologia, Hospital Clinic, Barcelona, Spain

3 Laboratorio de Hematología, Biología Molecular, Hospital Universitario de Gran Canaria Dr.Negrín, Las Palmas, Spain

4 Servicio de Hematología, Hospital Universitario Ramón y Cajal, IRYCIS, Madrid, Spain

5 Hematology Department, Hospital Universitari Vall d'Hebron, VHIO, Barcelona, Spain

6 Servicio de Hematología, Hospital Universitario Central de Asturias, Oviedo, Spain

7 Hematology Department, Imperial College Healthcare NHS Trust, London, UK

8 Servicio de Hematología, Hospital Universitari Mútua Terrassa, Terrassa, Spain

9 Instituto Investigación Sanitaria Aragón (IIS Aragon), CIBERER, Zaragoza, Spain
Ramírez-Payer, Eduardo Olavarria, Ferrán Vall-llovera, Pilar Giraldo, Eulogio Conde, Rolando Vallansot, Jose Luis López-Lorenzo, Luis Palomera, Alberto ÁlvarezLarrán, Venancio Conesa, Guiomar Bautista, Laura Casas, Frank Giles, Andreas Hochhaus, Luis Felipe CasadoMontero, was originally published Online First without open access.

After publication in volume 143, issue 10, pages 2059-2066 the authors decided to opt for Open Choice and to make the article an open access publication. Therefore, the copyright of the article has been changed to (C) The Author(s)

10 Hematologia, Universidad de Cantabria, Santander, Spain

11 Servei d'Hematologia, ICO-Tarragona, Hospital Universitari Joan XXIII, Tarragona, Spain

12 Hematologia, Clínica de la Concepción, Madrid, Spain

13 Hospital Clínico Universitario Lozano Blesa, Instituto Investigación (ISS) Aragón, Zaragoza, Spain

14 Hematology Department, Hospital del Mar-IMIM, Barcelona, Spain

15 Hematología, Departament de Salut d'Elx, Hospital General, Elche, Spain

16 Hematología, Hospital Puerta de Hierro, Madrid, Spain

17 Statistics Department, Dynamic Solutions, SL, Barcelona, Spain

18 Division of Hematology Oncology, Northwestern University Feinberg School of Medicine, Chicago, USA

19 Klinik für Innere Medizin II. Hämatologie/Onkologie, Universitätsklinikum Jena, Jena, Germany

20 Servicio de Hematología y Hemoterapia, Hospital Virgen de la Salud, Toledo, Spain 
2017 and the article is forthwith distributed under the terms of the Creative Commons Attribution 4.0 International License (http://creativecommons.org/licenses/by/4.0/), which permits use, duplication, adaptation, distribution and reproduction in any medium or format, as long as you give appropriate credit to the original author(s) and the source, provide a link to the Creative Commons license, and indicate if changes were made.
Open Access This article is distributed under the terms of the Creative Commons Attribution 4.0 International License (http://creativecommons.org/licenses/by/4.0/), which permits unrestricted use, distribution, and reproduction in any medium, provided you give appropriate credit to the original author(s) and the source, provide a link to the Creative Commons license, and indicate if changes were made. 